\title{
De Telefónica Media a Admira Media
}

\author{
Rosa del Valle Valero Naranjo \\ Grupo de Investigación en Estructura, Historia y Contenidos de la Comunicación \\ Coordinación: Dr. Ramón Reig (Universidad de Sevilla)
}

\section{RESUMEN}

En la presente investigación haremos un estudio del Grupo Telefónica Media y su cambio de nombre en el año 2001 por el de Admira Media. En este estudio se cuenta la evolución del grupo de comunicación en el panorama mediático español y su consolidación como grupo líder en el mercado de habla hispana y lusa, así como de las empresas que forman parte de Admira Media.

\section{ABSTRACT}

This letter investigation will make a study of the Telefónica Media Group and their change of name in the year 2001 for the of it Admira Media. It in this study are counted the evolution of the group of communication in the panorama Spanish massmedia and their consolidation like group leader in the Spanish-speaking market and portuguese, as well as of the companies that form part of you/he/she/it Admire Half.

Palabras claves: Telefónica Media/Admira Media/Grupo de comunicación/Líder.

Key Words: Telefónica Media/Admira Media/Group of communication/Leader.

\section{Introducción}

n los últimos 20 años, el mapa mediático español ha sufrido innumera-
bles cambios. La aparición de nuevos grupos de comunicación y la
creación de televisiones locales así como de periódicos regionales,
provinciales y locales de carácter privado, han provocado un terremoto mediático en un país acostumbrado a vivir a la sombra de una televisión y una radio pública y unos diarios controlados y afines, en cierta forma, al régimen existente.

Tras unos comienzos difíciles debido a diversos motivos políticos y económicos, TELEFÓNICA MEDIA se fue haciendo un hueco en el sector mediático español e internacional, favorecido también, como le había ocurrido años atrás a PRISA, por el sistema político gobernante, período que coincidió 
con la privatización de la compañía. Así, en un mundo tan competitivo y complejo como es en el que vivimos, TELEFÓNICA MEDIA ha sabido colocarse en una posición envidiable y ha establecido una maraña de relaciones que le han llevado a ser el grupo de comunicación líder en los mercados de habla hispana y lusa y ha pasado a llamarse ADMIRA MEDIA, por un simple sentido estético.

El principal objetivo de este trabajo es el de conocer más a fondo la estructura mediática del grupo TELEFÓNICA MEDIA. Sin embargo, a este primer objetivo hay que unirle otros y así conocer detalladamente diferentes cosas, como por ejemplo: cómo una empresa que se dedica originariamente a un negocio se plantea crear una filial de dicha empresa dedicada a las comunicaciones, cómo esa empresa filiar ha ido creciendo y se ha convertido en un ente importante dentro del sistema mediático nacional, conocer la manera en que esa empresa de las comunicaciones ha ido entablando relaciones con otras empresas del mismo sector mediante fusiones, participaciones, alianzas y acuerdos, cómo estas relaciones llevan a esta empresa a implantarse tanto en el territorio nacional como en el internacional y cuál es la manera en que mediante esas relaciones establecidas, la empresa ha llegado a convertirse en líder del sector audiovisual de habla hispana y lusa.

Utilizando tanto fuentes orales como fuentes escritas, la mayoría de la información necesaria para realizar este trabajo sobre la empresa la hemos conseguido de la página web de la empresa ADMIRA MEDIA www.ADMIRA.com y de TELEFÓNICA, S.A., www.telefonica.es como nos aconsejó la jefa del gabinete de comunicación de ADMIRA MEDIA, Flor Puente. Sin embargo, hemos mantenido también entrevistas telefónicas con dicha persona. Además, ante la imposibilidad de encontrar otra fuente de este tipo, nos centramos en diversos libros y documentos relacionados con el grupo de comunicación en cuestión, libros que trataran sobre el contexto mediático español actual y otros documentos referidos a las relaciones económicas mundiales y TELEFÓNICA, así como consultas a diversas páginas web.

\section{La situación mediática española}

En España los principales grupos de información/comunicación no pueden definirse como conglomerados aunque estén ligados a entidades financieras y a firmas extranjeras, pero se puede apreciar como tienen una tendencia hacia el conglomerado. Así, sólo dentro del mundo de la información y de su estudio podemos hallar tres expresiones: conglomerados de comunicación (toda función entre macroempresas ligadas total o parcialmente a la información), industrias culturales (grupo empresarial cuyas actividades están orientadas en un cien por cien a la elaboración de productos informativos) y grupos multimedia, concepto que llega a raíz de la anterior afección. En el conglomerado informativo estarían 
incluidas las otras dos expresiones, a parte de ser una concentración empresarial vertical. ${ }^{1}$

Nuestro país no posee aún conglomerados al estilo de países como EE.UU. y Francia, expresándose a través de asociaciones o acuerdos entre empresas procedentes del sector de las industrias culturales, las telecomunicaciones, otras grandes empresas atraídas por la posible rentabilidad, contando con el respaldo financiero correspondiente, sea en forma de crédito, de participación accionarial o de ambas modalidades. Así, se podría llegar a la conclusión de que la concentración en España sería, ante todo, horizontal en el sentido de que unas industrias culturales se diversifican dentro de un campo o absorben otras. De todas formas, la estructura informativa de España está protagonizada por unos pocos grupos que, a pesar de su implantación en nuestro país, tienen una posición muy secundaria en el contexto europeo y una escasa relevancia mundial.

Se podría decir que España tiende a la concentración, pero también a la localización, aunque hallamos tendencias "centrífugas" en los receptores y en la estructura informativa, cosa que deriva, en parte, de la propia concentración y globalización, ya que da la impresión de que los receptores se muestran reticentes, temerosos ante un mundo que avanza a unas velocidades de vértigo gracias al rápido desarrollo de las nuevas tecnologías.

Esto, unido a la acumulación de rasgos históricos consuetudinarios, hace que los receptores demuestren interés por saber de un acontecimiento mundial al tiempo que anhelan conocer la actualidad de su entorno más inmediato y cotidiano. Aparecen, así, tanto medios locales y regionales o zonales a la vez que los grandes grupos de información que añaden complejidad a la información pero que a la vez la simplifican gracias a las nuevas tecnologías, tanto en prensa como en radio y televisión.

1 REIG, Ramón: Medios de comunicación y poder en España: prensa, radio, televisión y mundo editorial, Paidós PC, Barcelona, 1998. 


\section{GRUPOS DE COMUNICACIÓN EN ESPAÑA ${ }^{2}$}

\begin{tabular}{|c|c|c|}
\hline \multicolumn{3}{|l|}{ PLANETA } \\
\hline - PRENSA & Editorial Martínez Roca & - TELEVISIÓN \\
\hline La Razón & $\begin{array}{l}\text { Planetas Grandes Obras } \\
\text { Ediciones Destino }\end{array}$ & RTV Sant Celoni 60\% \\
\hline - $\underline{\text { REVISTAS }}$ & Plawerg Editorial $50 \%$ & - $\underline{\mathrm{RADIO}}$ \\
\hline Ediciones Altaya $25 \%$ & $\begin{array}{l}\text { Espasa Calpe } 67 \% \\
\text { Insula } 67 \%\end{array}$ & $\begin{array}{l}\text { Radio Popular } 11 \% \\
\text { RKOR }\end{array}$ \\
\hline - $\underline{\text { LIBROS }}$ & Gr. Planeta Agostini $50 \%$ & \\
\hline Editorial Planeta & Ed. Planeta Agostini 50\% & - CINE/PRODUCCIÓN \\
\hline Editorial Seix Barral 98\% & Editorial Deusto $75 \%$ & Planeta 2010 \\
\hline $\begin{array}{l}\text { Editorial Ariel } 98 \% \\
\text { Editorial Temas de Hoy }\end{array}$ & Editorial Geoplaneta & \\
\hline
\end{tabular}

\begin{tabular}{|c|c|c|}
\hline \multicolumn{3}{|l|}{ PRISA } \\
\hline - PRENSA & - TELEVISIÓN & R. España Barcelona 99\% \\
\hline El País & Localia TV - 53 emisoras & Radio Murcia $83,3 \%$ \\
\hline Cinco Días & Localia Galicia $60 \%$ & Grupo Latino Radiodifusión \\
\hline AS $75 \%$ & Canal 4 de Navarra $51 \%$ & In. R. C. La Mancha $50 \%$ \\
\hline Diario de León $59,3 \%$ & Localia TV Madrid & Promotora de Emisoras \\
\hline El Correo de Andalucía & Prod. Aud. Badajoz 51\% & Teleser $72 \%$ \\
\hline El Día de Valladolid $60 \%$ & Prod. Extremeña TV $51 \%$ & Unión Radio Digital \\
\hline Odiel Información & $\begin{array}{l}\text { Prom. Audiov. Canarias } \\
\text { P. Audiov. Sevillanas } 70 \%\end{array}$ & $\begin{array}{l}\text { Antena } 3 \text { Radio 49,3\% } \\
\text { Antena } 3 \text { León 49,1\% }\end{array}$ \\
\hline$\frac{\text { - SUPLEMENTOS }}{\text { Ediciones La Mirada }}$ & Alianzas Com. 48,7\% & $\begin{array}{l}\text { Antena } 3 \text { Melilla 49,3\% } \\
\text { Cadena Onda Oliva 49,3\% }\end{array}$ \\
\hline & - CABLE & \\
\hline - $\underline{\text { REVISTAS }}$ & Cable Antena $21,27 \%$ & - MÚSICA \\
\hline Progresa-Rolling Stones, & & Muxxxxic Records \\
\hline Cinemanía y otras & - $\underline{\text { PUBLICIDAD }}$ & Eurotropical Prod... \\
\hline Box News $22,5 \%$ & Gerencia de Medios & Gran Vía distrib.... 70\% \\
\hline & Ociomedia Producciones & Gran Vía Musical Ed. 50\% \\
\hline - $\underline{\text { LIBROS }}$ & GDM Publi. Electr. 51\% & Nova Ediciones Musicales \\
\hline Aguilar Comercial & & Sogecaable Música \\
\hline
\end{tabular}

2 AUSBANC: «Los nueve gigantes de la comunicación» Nº1, Madrid, Marzo 2002, pp. 50-54. 


$\begin{array}{lll}\text { Canal de Editoriales } 95 \% & -\underline{\text { RADIO }} & \\ \text { Ediciones El País } & \text { Ser } & -\underline{\text { MULTIMEDIA }} \\ \text { Ediciones Grazalema } & \text { Cadena 40 } & \text { Prisacom } \\ \text { Ediciones Obradoiro } & \text { Cadena Dial } & \text { Net Lenguajes 67\% } \\ \text { Ediciones Voramar } & \text { Radio Olé } & \\ \text { Editorial Mangold } & \text { Unión Radio 80\% } & -\underline{\text { OTROS }} \\ \text { Grup Promotor } & \text { Radio Zaragoza } & \text { Distribuciones Aliadas } \\ \text { Gr. Santillana de Ediciones } & \text { Algarra } & \text { Ediciones Bidasoa } \\ \text { N Editorial } & \text { Avante Radio } & \text { Eje Comunicación Andaluza } \\ \text { Santillana Canarias } & \text { Comunicación Radiofónica } & \text { Gelesa 50\% } \\ \text { Zubía Editoriala } & \text { Corp. Canaria de TV y Radio } & \text { Itaca } \\ & \text { Inic. Radiofónicas 93,42\% } & \text { Mateu Cromo Art. Gráficas } \\ & & \\ \text { - TELEVISIÓN DE PAGO } & \text { Ondas } & \text { Viajes Crisol } \\ \text { Sogecable 21\% } & \text { Ondas Galicia 42,4\% } & \text { Audiovisual Sport 8,5\% } \\ \text { Canal + } & \text { Radiodifusión Tenerife } & \text { Media Festivals } \\ \text { Canal Satélite Digital } & \text { Radio Club Canarias 95\% } & \text { Otros }\end{array}$

\section{PRENSA IBÉRICA}

- PRENSA

Diario Las Palmas 90,13\% Información Alicante

La Nueva España

Levante Faro de

Diario de Ibiza $91 \%$

Prom. Inf. D,Osona

Diario de Mallorca 96,5\%

La Opinión Málaga

La Opinión La Coruña

La Opinión Tenerife

Mallorca Zeitung

Diari de Girona

La Opinión de Murcia 91\% Alba Editorial

El Correo de Zamora 91\% Allison \& Busby $94 \%$

Estadio Deportivo 15\%
- SUPLEMENTOS

La Vanguar. Magazine 50\%

- $\underline{\text { CABLE }}$

Vigo Vigocable

-MULTIMEDIA

Prensa Ibérica Media

Pren. Asturiana Media 95\%

Faro de Vigo Media 95\%

Prensa Canaria Media 90\%

- LIBROS

$\%$ Allison \& Busby $94 \%$

\section{-OTROS}

Celta de Artes Gráficas Corp. Gráfica Penibética Arts Graf. De Girona 95\% Liberduplex Pren. Ib. Management 96\%

A. Graf. Mediterráneo $81 \%$

A. Graf. del Atlántico $90 \%$

A. Graf. del Principado

A. Graf. de Baleares 96\% Impresión Prensa 90\% Sistema de Prensa 91\% Val Dilme 22,7\%

Grup Logistic Vilarroya 5\% Editorial de Prensa Local 


\begin{tabular}{|c|c|c|}
\hline \multicolumn{3}{|c|}{ CORREO PRENSA ESPAÑOLA } \\
\hline - PRENSA & - MULTIMEDIA & Com. Media Levante $96,9 \%$ \\
\hline El Correo Español & Gr. Correo M. Trader & Publiespaña $25 \%$ \\
\hline $\mathrm{ABC}$ & Sarenet $80 \%$ & Mediasal 2000 34,7\% \\
\hline Diario Vasco $70,6 \%$ & La Verdad Digital $96,9 \%$ & JPSaferi $87 \%$ \\
\hline La Verdad Murcia 96,9\% & Ideal Com. Digital 97\% & Biboguía 30,6\% \\
\hline Ideal Granada $97 \%$ & Ed. Digitales Hoy 95,7\% & Globalia \\
\hline Hoy Extremadura 95,7\% & Norte Castilla Digital 75,9\% & \\
\hline Sur de Málaga $87 \%$ & El Comercio Digital 51,5\% & - OTROS \\
\hline Dario Montañés 73,3\% & La Ciudad Interac. $33,3 \%$ & Beralán $75 \%$ \\
\hline La Rioja 58,9\% & Digital Vasca 70,6\% & Bilbao Ed. Prod. \\
\hline El Norte de Castilla $75,9 \%$ & El Correo Digital & Soc. Vasc. Producc. 70,6\% \\
\hline El Comercio 51,5\% & La Rioja Com. 58,9\% & Sector MD 38,3\% \\
\hline La Voz de Avilés $43,7 \%$ & Diario Sur Digital $87 \%$ & Distrib. Papiro $28 \%$ \\
\hline Las Provincias $30,1 \%$ & Fiera Elec. Retailing 33,3\% & Corp. Medios Telef. $36 \%$ \\
\hline Tribuna Ciudad Real & ABC Electrónico & Cotlan $90060 \%$ \\
\hline Tribuna Guadalajara 75\% & & Serv. Redacc. Bilbaínos \\
\hline Tribuna Toledo $75 \%$ & - TELEVISIÓN & Keliox $60 \%$ \\
\hline \multirow[t]{2}{*}{ Tribuna Cuenca $75 \%$} & Tele $525 \%$ & Sentinel Security $60 \%$ \\
\hline & M. Visión-Málaga 60,9\% & Serv. Aux. Prensa 45,5\% \\
\hline -SUPLEMENTOS & Teledonosti $30,7 \%$ & Atlas País Vasco 55,1\% \\
\hline Taller de Editores $53,1 \%$ & Rioja Televisión 24,9\% & Distr. Prensa Rutas $20 \%$ \\
\hline \multirow[t]{2}{*}{ Mediatika $50 \%$} & Canal Bilbovisión 70\% & Huelva Impresión 89\% \\
\hline & Huelva Televisión $53 \%$ & Soporte Int. de Prensa \\
\hline - $\underline{\text { REVISTAS }}$ & Telemadroño $40 \%$ & \\
\hline \multicolumn{3}{|c|}{ Taller de Edit. Corp. 53,5\% Net TV $25 \%$} \\
\hline \multicolumn{3}{|c|}{ Inversor Ediciones $15,9 \%$ Onda $6 \mathrm{TV} 40 \%$} \\
\hline Zabalik $200085,3 \%$ & Canal Cult. Badajoz 51\% & \\
\hline \multicolumn{3}{|c|}{ Gratuitos C. Med. 60,3\% } \\
\hline \multicolumn{3}{|c|}{ Estudios Pol. Exterior $30 \%$ - CINE/PRODUCCIÓN } \\
\hline & Producc. Dig. Sur $63,5 \%$ & \\
\hline -RADIO & Cristal Prod. Cinem. $30 \%$ & \\
\hline Radio Popular $4 \%$ & Gr. Europroducciones $30 \%$ & \\
\hline \multicolumn{3}{|l|}{ Radio Telebasconia } \\
\hline \multicolumn{3}{|c|}{ Corp. Medios Vascos 55\% - PUBLICIDAD } \\
\hline \multicolumn{3}{|c|}{ Corp. Med. Rioja 58,9\% CM Norte } \\
\hline \multicolumn{3}{|c|}{ Corp. Med. Digitales $92,5 \%$ CM XXI } \\
\hline e-media Punto Radio & Rioja Medios $58,9 \%$ & \\
\hline Onda Médica Sevilla $50 \%$ & Corp. Medios Sur $87 \%$ & \\
\hline
\end{tabular}




\begin{tabular}{|c|c|c|}
\hline \multicolumn{3}{|l|}{ ZETA } \\
\hline - PRENSA & - SUPLEMENTOS & -OTROS \\
\hline El Periódico de Catalunya & Med. Gestora Medios 50\% & Zeta Servicios y Equipos \\
\hline El Periódico Medite. $83 \%$ & & Gráficas de Prensa Diaria \\
\hline \multicolumn{2}{|c|}{ El Adelandado de Salamanca -MULTIMEDIA } & Inic. Publi. Impresión 69\% \\
\hline El Periódico de Aragón & Zeta Digital & Impre. Asturiana Gráfica \\
\hline La Voz de Asturias & Dicom Medios $80 \%$ & Serv. Impresión Aragón \\
\hline \multirow{2}{*}{\multicolumn{2}{|c|}{$\begin{array}{l}\text { El Periódico de Extremadura Zeta Multimedia } \\
\text { Equipo }\end{array}$}} & Gestión e Impresión \\
\hline & & Serv. Impr. Levante $62 \%$ \\
\hline Córdoba $69 \%$ & - $\underline{\text { RADIO }}$ & Serv. de Impr. Oeste \\
\hline Ciudad de Alcoy $75 \%$ & Grupo Zeta Radio & Prom. y Desarrollo $89 \%$ \\
\hline El Periodic d'Andorra 33\% & Onda Catalana $35 \%$ & Distribuciones Periodísticas \\
\hline Sport $90,1 \%$ & Radiofonía Aragonesa & Logística de Medios \\
\hline Ontinyent Edicions $80 \%$ & Radio Sport Catalun. $78 \%$ & Logística Medios Catalunya \\
\hline \multirow[t]{2}{*}{ El Periódico de Alicante } & Radiof. Mediterránea $71 \%$ & Distribuciones Gracia 25\% \\
\hline & Radio La Voz de Asturias & Grup Log. Vilarroya 22\% \\
\hline - $\underline{\text { REVISTAS }}$ & Prod. Inform. Mediterráneas & Distr. Tarraconense $38 \%$ \\
\hline Com. y Medios de Aragón & Onda Mezquita $66 \%$ & Cirpress $12 \%$ \\
\hline Com. y Medios de Levante & & Segre Distribucions $25 \%$ \\
\hline Guies Locals Catalun. $45 \%$ & - $\underline{\text { LIBROS }}$ & \\
\hline Ediciones Zeta-Interviú & Ediciones B & \\
\hline Tiempo y otras & Suma de Letras $50 \%$ & \\
\hline \multicolumn{3}{|l|}{ Ediciones Reunidas } \\
\hline & - $\underline{\text { PUBLICIDAD }}$ & \\
\hline - TELEVISIÓN & Pequeños Anuncios & \\
\hline Antena Local 50\% & ISO & \\
\hline
\end{tabular}

\begin{tabular}{|c|c|c|}
\hline \multicolumn{3}{|l|}{ RECOLETOS/UNEDISA } \\
\hline - PRENSA & - $\underline{\text { LIBROS }}$ & - OTROS \\
\hline Expansión & La Esferas de Libros $75 \%$ & Recoprint Impresión \\
\hline Marca & & Rec. Pinto \\
\hline Diario Médico & - TELEVISIÓN & Rec. Dos Hermanas \\
\hline El Mundo & Veo TV $51 \%$ & Rec. Sagunto \\
\hline El Mundo P. Vasco $82,6 \%$ & & Rec. Rábade \\
\hline El Mundo Catalunya $61,6 \%$ & - $\underline{\text { RADIO }}$ & Rec. Guimar: Red de \\
\hline ED. Medios C. y L. 69,3\% & Canal Mundo Radio & Gelesa $35 \%$ \\
\hline E.M. - El Día Baleares 51\% & & Distrimedios \\
\hline El Mundo Valencia $52 \%$ & - CINE/PRODUCCIÓN & Logintegra \\
\hline La Crónica de León $10 \%$ & Canal Mundo Producciones & Euskalprint $83 \%$ \\
\hline & Tesamun $49,9 \%$ & Fabripress \\
\hline
\end{tabular}




\begin{tabular}{|c|c|c|}
\hline - $\underline{\text { REVISTAS }}$ & Nexum $49,9 \%$ & Calprint $69 \%$ \\
\hline Pool de Medios & & Omni $51 \%$ \\
\hline Arlanza ediciones $75 \%$ & - MULTIMEDIA & Omniprint $23 \%$ \\
\hline Ediservicios & \multicolumn{2}{|c|}{ Ciudad Interactiva $33,33 \%$} \\
\hline Magamundi $49 \%$ & & - PUBLICIDAD \\
\hline & -SUPLEMENTOS & Novomedia \\
\hline & EdicionesCrónica & Unedisa Publicidad \\
\hline \multicolumn{3}{|l|}{ ADMIRA MEDIA } \\
\hline - MULTIMEDIA & - MÚSICA & Lola Films \\
\hline ArtMedia & $\begin{array}{l}\text { Grupo Fama } \\
\text { ST Hilo }\end{array}$ & Megatriz \\
\hline - TELEVISIÓN & & $\underline{\mathrm{RADIO}}$ \\
\hline Antena $3 \mathrm{TV}$ & $\begin{array}{l}\text { - } \text { CINE/PRODUCCIÓN } \\
\text { Endemol } 25 \%\end{array}$ & Uniprex \\
\hline - TV DE PAGO & Mediapark & \\
\hline Vía Digital $49 \%$ & ADMIRA Sport & \\
\hline ADMIRA Servicios & Audiovisuales Audiovisual S & port \\
\hline
\end{tabular}

\begin{tabular}{|c|c|c|}
\hline \multicolumn{3}{|c|}{ GODÓ COMUNICACIÓN } \\
\hline - PRENSA & - SUPLEMENTOS & - MULTIMEDIA \\
\hline La Vanguardia & La Vanguar. Magazine $50 \%$ & La Vanguardia Digital \\
\hline El Mundo Deportivo & & La Ciudad Interact. $33,33 \%$ \\
\hline Ed. Intercomarc. $3 \%$ & - $\underline{\text { REVISTAS }}$ & Movendus Portal $15 \%$ \\
\hline & La Vanguardia Publicaciones & Servijob $50 \%$ \\
\hline - TELEVISIÓN & Mundo Revistas & Servihabitat $32 \%$ \\
\hline City TV & $\begin{array}{l}\text { Vang-3 Publicaciones } 50 \% \\
\text { Promoedi }\end{array}$ & Innova $31.10 \%$ \\
\hline -CABLE & & - OTROS \\
\hline Tisa Cable $50 \%$ & - $\underline{\text { PUBLICIDAD }}$ & La Vanguardia Servicios \\
\hline & Publipress Organización & Gestión Prod. Editoriales \\
\hline - $\underline{\text { RADIO }}$ & New Ad Publicity $25 \%$ & Gestión Domiciliaria Prensa \\
\hline Catalunya Comunicació & Guías de ciudad $50 \%$ & Distribución y Reparto \\
\hline Radiocat $85 \%$ & & Riuclar Distrib. $48 \%$ \\
\hline Antena 3 Radio $50 \%$ & - MÚSICA & Gr. Logistic Vilarroya $22 \%$ \\
\hline Onda Musical 25,35\% & GDA Disc & Segre Distribucions $25 \%$ \\
\hline SSR Unión Radio $20 \%$ & & Atlas Cataluña $50 \%$ \\
\hline & & Gelesa $5 \%$ \\
\hline & & Val-Disme $5 \%$ \\
\hline
\end{tabular}




\begin{tabular}{|c|c|c|}
\hline \multicolumn{3}{|l|}{ HERALDO DE ARAGÓN } \\
\hline - PRENSA & - $\underline{\text { RADIO }}$ & - CABLE \\
\hline Heraldo de Aragón & Soc. Radio Aragonesa 50\% & Auna $0,07 \%$ \\
\hline & - SUPLEMENTOS & - OTROS \\
\hline - MULTIMEDIA & Taller de editores $14,07 \%$ & Distribuidora de Aragón \\
\hline Ciud. Inter. Zaragoza. 60\% & & Serv. Reparto Distribución \\
\hline & - $\underline{\text { PUBLICIDAD }}$ & Talleres Gen. Impr. Aragón \\
\hline - TELEVISIÓN & ubliprinsa $30,7 \%$ & \\
\hline Antena Aragón $15 \%$ & & \\
\hline
\end{tabular}

\section{PROMECAL}

- PRENSA

Diario de Burgos

Diario de Miranda

Diario Palentino

Diario de Ávila $88 \%$

El Día de Valladolid 40\%

Burgos Ocasión

- MULTIMEDIA

Diario de Burgos Digital
- SUPLEMENTOS

Taller de Editores

- TELEVISIÓN

Canal 4 Castilla y León

Televisión de Valladolid

Comunicaciones Carrión

Veo televisión
- $\underline{\text { CABLE }}$

TELEFÓNICA Cable de C. y L.

- OTROS

Firstmark Com. 1,5\%

Diario Burgos Taller Imp.

Gestión Medios de Prensa

\section{VOZ}

- PRENSA

La Voz de Galicia

Diario de León

- MULTIMEDIA

Canal Voz

- $\underline{\text { REVISTAS }}$

Gacetas Locales de Castilla y León 49,9\%

\section{- OTROS}

Voz de Galicia Radio

Distr. Gallega de Public.

Noroeste de Radiodifusión

Instituto Sondaxe

Radio Arco Atlántico

Radio Marineda 47\%

- CINE/PRODUCCIÓN

NTR Telefábrica

Agrela Multimedia 


\begin{tabular}{|c|c|c|}
\hline \multicolumn{3}{|l|}{ SERRA } \\
\hline - PRENSA & - TELEVISIÓN & - $\underline{\text { REVISTAS }}$ \\
\hline Última Hora & Nová Televisió & Prenshora \\
\hline Majorca Daily Bulletin & Canal 37 & \\
\hline RADIO & & - OTROS \\
\hline Última Hora Radio & & \\
\hline
\end{tabular}

\begin{tabular}{|c|c|c|c|}
\hline JOLY & & & \\
\hline $\begin{array}{l}\text { - PRENSA } \\
\text { Diario de Cádiz }\end{array}$ & Diario de Jerez & Europa Sur & Huelva Información \\
\hline
\end{tabular}

\section{TELEFÓNICA MEDIA ${ }^{3}$}

TELEFÓNICA MEDIA es el sector dedicado a las comunicaciones de la empresa TELEFÓNICA, S.A.. Antes y después de su privatización a partir de 1995, la empresa había indicado desde hacía ya algún tiempo que era preciso considerar a esta empresa como un grupo comunical y telecomunical emergente y con amplias ramificaciones hacia el exterior. Así, se crea TELEFÓNICA Media.

A mediados de los 90, TELEFÓNICA inició su actividad en los negocios audiovisuales con el objetivo de distribuir contenidos en el mercado de habla hispana. Las inversiones en medios audiovisuales se convirtieron en una opción de futuro al agrupar servicios de telecomunicaciones, información y entretenimiento. Con estos propósitos se creó la empresa Distribuidora de Televisión Digital, bajo la marca Vía Digital, y se adquirió una parte del capital de Antena 3 TV.

TELEFÓNICA MEDIA es un conjunto empresarial integrado por cerca de 70 compañías de servicios de telecomunicaciones y medios de comunicación, estructuradas bajo un esquema organizativo claramente orientado al mercado y con el objetivo de ofrecer una respuesta eficaz a las necesidades de los más de 54 millones de clientes.

Como operador con una vocación global, TELEFÓNICA realiza inversiones y gestiona compañías en diferentes partes del mundo, pero con mayor intensidad en Iberoamérica, su mercado natural y el destino de sus principales actuaciones durante la última década.

3 www.ADMIRA.com 
En 1999 se puso de manifiesto el doble cambio de matriz en el sistema español de medios. Una transformación tecnológica, con una clara orientación hacia el escenario digital multimedia, y el cambio de escala económica, especialmente por la rápida ocupación mediática de TELEFÓNICA, con alcances significativos en América Latina, especialmente en Argentina. La apuesta de TELEFÓNICA, una vez culminada su privatización, gozó del acompañamiento gubernamental, que le permitió diversificar más fácilmente sus actividades y entrar en las distintas opciones del negocio audiovisual. Se sobrentendía que los espacios ocupados por la compañía de telecomunicaciones pasaban a formar parte de un tácito grupo progubernamental, en un momento de alta tensión política definido como 'guerra de medios', en el que el grupo Prisa, cuyo crecimiento se vinculaba desde las posiciones conservadoras a los favores gubernamentales del partido socialista, pasaba a ser un objetivo a batir. Una de las razones esgrimidas contra Prisa - el 'monopolio' para sus contrincantes- era la dimensión que había alcanzando a mediados de los 90, argumento atenuado por el peso de los hechos y la celeridad con la que fue construyéndose el nuevo grupo, con extensiones y alianzas que le daban presencia en todos los ámbitos de la comunicación.

El continuo primer plano de TELEFÓNICA en la compra de medios, obtención de licencias y concesiones gubernamentales, ajustes legales, etc., relegó la actividad del resto de los grupos a un segundo plano. El año 2000 se convirtió, especialmente después de la salida de Juan Villalonga de la presidencia de TELEFÓNICA y del triunfo electoral del Partido Popular, en un período de aparente reflujo de pasadas tensiones y de replanteamiento del modelo del grupo nacido de la compañía privatizada, que parece buscar una gestión más profesional e incluso neutralizar pasadas tensiones ${ }^{4}$.

Antes del cambio de presidencia, se llevaron a cabo tres grandes operaciones. Tachadas de precipitadas, arriesgadas y producto de una dirección mesiánica de la compañía por algunos accionistas de referencia y por medios de comunicación antes próximos a Villalonga, la crítica se acentuó especialmente cuando comenzó a debilitarse la sintonía de éste con el presidente del Gobierno y sus golpes de timón se interpretaron como un verdadero pulso político. ${ }^{5}$ Así, las compras de Lycos, Endemol y MediaWays, por un valor conjunto de más de 4 billones de pesetas, se produjeron bajo un criterio estratégico de corporación global, pero suponían un estiramiento excesivo del perímetro de la compañía en

4 INFORME ANUAL DE LA COMUNICACIÓN (2000-2001), Grupo Zeta, Madrid, 2001, p. 43.

5 Así, en junio de 2000, se anunció un acuerdo entre TELEFÓNICA y Prisa en los ámbitos de Internet y televisión digital, mediante un posible intercambio de acciones que tendría como resultado el liderazgo en el espacio de lengua española. El acuerdo, del que no volvió a hablarse tras la salida de Villalonga, dejaría en manos de Prisa la provisión de contenidos, mientras que TELEFÓNICA pondría los resultados tecnológicos. El vicepresidente del Gobierno, Rodrigo Rato, declaró que vigilaría el acuerdo para impedir que se vulnerase la libre competencia del sector. (EL MUNDO, 9.6.2000) 
muy poco tiempo y, especialmente, una elevada incertidumbre ante la amenaza de crisis de la llamada 'nueva economía', esto es, de purga mercantil de aquellos valores tecnológicos que ofrecían poco más que una vaga y artificial seducción de futuro. Tras la cortina de una economía nueva, los grandes grupos asistían a los mayores procesos de concentración de la historia y descubrían, en realidad, que la máxima novedad del momento radicaba en los espacios de diversificación y expansión derivada de dos fenómenos paralelos, la desregulación y el desarrollo de estrategias de uso mercantil de las tecnologías de la información. Esto es, el traslado al plano de las grandes corporaciones de los resortes de la innovación, incluidos los tecnológicos, como instrumentos determinantes de las modas y del consumo.

El 17 de marzo de 2000 TELEFÓNICA anunció su OPA sobre la productora audiovisual holandesa Endemol, presentada entonces como la mayor de Europa, por un valor inicial de 915.000 millones de pesetas. Con filiales en 17 países y una producción anual próxima a los 100 programas de televisión, era la propietaria de Gran Hermano, programa que sería estrenado en España un mes después en Tele 5, esto es, en la televisión competidora del canal de TELEFÓNICA (Antena 3). El grupo holandés era exhibido como una pieza central en el proyecto de liderazgo de TELEFÓNICA, cuya penetración en América Latina le permitiría extender su espacio de distribución de programas. La operación fue anunciada cuando Pearson y Bertelsmann negociaban la integración de sus activos audiovisuales en el grupo RTL, pero también cuando TELEFÓNICA y Bertelsmann buscaban acuerdos estratégicos, entre los que se incluía la entrada de los alemanes en el capital de Antena 3. La compra de Endemol supuso un distanciamiento entre TELEFÓNICA y Pearson, del que la compañía española era accionista desde el año anterior, ya que el grupo británico había manifestado su interés por los activos de Endemol y alcanzar así la supremacía como productor audiovisual en Europa.

La oferta pública de TELEFÓNICA sobre Endemol concluyó el 24 de julio de 2000, dos días antes de la salida anunciada de Villalonga de la presidencia de la compañía española. Con posterioridad, TELEFÓNICA amplió su presencia en el campo de derechos deportivos, donde ya operaba en Audiovisual Sport, con la creación de TELEFÓNICA Sport y de Euroleague Marketing, sociedad en la que posee el 70 por ciento y controla los derechos y explotación comercial de esta liga europea de baloncesto con 24 equipos, entre ellos el Real Madrid y el Barcelona.

Dos meses después de la OPA de Endemol, se anunció la compra del proveedor de acceso a Internet Lycos, por un valor de 12.500 millones de dólares (2,28 billones de pesetas), lo que, en apariencia, situaba a TELEFÓNICA, en el campo de Internet, detrás de América Online y Yahoo!. La estructura nacida de la compra de Lycos le daba la primacía, según comunicado de la empresa, en 
Canadá, Corea del Sur, América Latina y el mercado hispano de Estados Unidos: la segunda posición en Asia, la tercera en Europa y la cuarta en Estados Unidos; Terra-Lycos pasaba a operar a través de filiales en 40 naciones, 122 sitios en 19 idiomas distintos y 91 millones de visitantes al mes. Con anterioridad, TELEFÓNICA ya había establecido una extensa estructura en Internet a través de América Latina, mediante la compra de portales de referencia en la mayoría de las naciones de habla hispana.

En junio, semanas antes del cambio en la presidencia de TELEFÓNICA, la filial Telefónica Data compró MediaWays a Bertelsmann, considerada como la mayor operadora alemana en redes para Internet después de Deutsche Telekom, por un valor próximo a los 300.000 millones de pesetas (1.600 millones de dólares). A la vez, se cerraba un acuerdo entre Bertelsmann y TELEFÓNICA para crear una sociedad, controlada por el grupo alemán (75 por ciento), de distribución de libros en España y América Latina a través de Terra Lycos. Bertelsmann.

América Latina sigue siendo el principal punto de mira en la propuesta de globalización de la compañía. En marzo de 2001, Emergia, filial de TELEFÓNICA con sede en Montevideo, proveedora de infraestructuras de banda ancha, concluyó la construcción de un anillo submarino de 25.000 kilómetros de fibra óptica, que conecta Estados Unidos con el Centro y el Sur del continente en un doble trazado, por el Atlántico y por el Pacífico. La red, con una alta capacidad de tráfico, tiene extensiones terrestres hasta las ciudades de Buenos Aires, Sao Paulo, Río de Janeiro, Santiago de Chile, Lima, Ciudad de Guatemala y San Juan de Puerto Rico.

En el plano local de los medios, TELEFÓNICA, propietaria entre otras compañías de Antena 3 y Onda Cero, forma parte de la que se entiende como estrategia de proximidad al Gobierno de Madrid, tendente a la creación de un amplio grupo multimedia, en el que se integrarían los intereses de Pearson y Unidad Editorial, que han ampliado y diversificado su actividad a través de nuevas extensiones en los campos de la radio analógica y digital, así como en los distintos estándares de televisión digital. En abril de 2000, las emisiones de radio de Recoletos y Unedisa se unieron a Onda Cero en un acuerdo que, inicialmente, se circunscribe a los contenidos informativos. En septiembre de 2000, TELEFÓNICA anunció la reestructuración de TELEFÓNICA MEDIA en tres áreas de negocio: televisión en abierto y radio, con Antena 3, Telefé y Onda Cero como referencias; contenidos, que gira en tomo a Endemol; y televisión de pago, con Vía Digital como primer activo.

Con las últimas adquisiciones realizadas en Brasil, la compañía está presente en los mercados más importantes de la región, como Argentina, Brasil, Chile, Perú, Puerto Rico, El Salvador, Guatemala, Colombia y Venezuela. Por otro lado, dentro de la estrategia de consolidación en Europa, la adquisición de European 
Telecom de Austria inauguró una nueva fórmula de desarrollo de oportunidades de negocio a través de operadores alternativos, que ha tenido su continuación en Italia.

A partir del liderazgo en los servicios de comunicación de voz y de transmisión de datos, del desarrollo de la televisión de pago y de los servicios de acceso a la información, interactivos y multimedia, TELEFÓNICA con una visión global del negocio y una mentalidad abierta a la innovación continua y al desarrollo de alianzas, pretende aprovechar todas las oportunidades que presenta la convergencia del sector para alcanzar una masa crítica significativa a escala mundial y mejorar su posición competitiva en el mercado, convirtiéndose en el primer operador europeo por capitalización bursátil y en el quinto grupo mundial de las telecomunicaciones.

\section{OBJETIVOS DE LA EMPRESA}

Las nuevas tecnologías digitales que amplían las posibilidades del sector audiovisual y la redefinición de los marcos regulatorios nacionales y supranacionales han dado un dinamismo inusitado al negocio de la comunicación. Este nuevo escenario propicia la aparición de grandes grupos multimedia fruto de fusiones y alianzas, y confiere a los contenidos la función de elemento fundamental de diferenciación entre las distintas ofertas. Ante la nueva realidad TELEFÓNICA ha reagrupado todas sus actividades de los sectores de medios y contenidos en un gran grupo de carácter multinacional: TELEFÓNICA MEDIA.

TELEFÓNICA MEDIA es el grupo de comunicación que aglutina las actividades de media y contenidos de TELEFÓNICA. En estos momentos TELEFÓNICA MEDIA está en una fase de expansión y afianzamiento de su participación en diferentes medios de comunicación, en los que ya ha invertido 400.000 millones de pesetas.

El nuevo presidente de la compañía, Juan José Nieto, no ha expresado públicamente su intención de transformar significativamente los proyectos estratégicos de su predecesores en TELEFÓNICA. Su punto de partida, sin embargo, le proporciona un amplio margen de maniobra. Sin embargo, sí que se ha producido un cambio significativo en lo que a imagen se refiere.

\section{CAMBIO DE NOMBRE: ADMIRA MEDIA}

En el último semestre del 2001, TELEFÓNICA MEDIA cambió de nombre, denominándose ADMIRA MEDIA de acuerdo con la estrategia de desarrollo de la filial de telefónica que agrupa las participaciones del grupo en medios de comunicación, aprobada por el Consejo de Administración de la compañía en su reunión del 6 de septiembre de 2001, a propuesta de su presidente, Juan José Nieto. 
ADMIRA es la respuesta de TELEFÓNICA a las nuevas demandas de información, entretenimiento y servicios de la sociedad del Siglo XXI. Abarca todas las áreas de creación y distribución del mercado audiovisual y es líder en 'media tradicional' (televisión y radio) en lengua española y portuguesa. ADMIRA es el primer productor mundial de contenidos de entretenimiento a través de su filial ENDEMOL. Más de 9.000 personas trabajan en este grupo, que aúna empresas con una facturación anual próxima a los 3.000 millones de euros.

ADMIRA está presente en cuatro continentes y 23 países (Alemania, Argentina, Australia, Bélgica, Brasil, Dinamarca, España, Estados Unidos, Finlandia, Francia, Holanda, Italia, Méjico, Noruega, Nueva Zelanda, Perú, Polonia, Portugal, Reino Unido, Sudáfrica, Suecia, Suiza y Venezuela) y se estructura en tres líneas de negocio: televisión en abierto y radio, contenidos y televisión de pago. Al cierre del primer semestre, el grupo obtuvo un EVITAD (resultado operativo) de 69 millones de euros. A 30 de junio de 2001, ADMIRA consiguió, por primera vez en sus cuatro años de historia, un resultado de explotación positivo (EVITAD menos amortizaciones). Así, a 30 de junio ganó 30 millones de euros. ${ }^{6}$

La nueva denominación abandera el compromiso de ADMIRA de competir con personalidad de marca y voz diferenciada en el sector de media en el nivel internacional. Además, ADMIRA favorecerá la consolidación de una identidad y cultura de grupo, actuando como aglutinante de las diversas compañías del grupo.

Los atributos positivos que los estudios atribuyen a la nueva marca son, entre otros, los siguientes: ADMIRA es una marca de 'relación' y ADMIRAción recíproca, sugiere una compañía que sorprende a sus clientes con su creatividad y, además, es un nombre semántica y fonéticamente accesible desde cualquier idioma a las audiencias internacionales del grupo. Junto a esto hay que añadir que ADMIRA es una marca claramente diferenciada en el ámbito competitivo ${ }^{7}$. El grupo ADMIRA se posiciona en el mercado como líder en creación, empaquetado y distribución de contenidos en medios tradicionales y multiplataformas, con proyección internacional. ADMIRA tiene voluntad, además, de consolidar su posición como primer proveedor de contenidos de TELEFÓNICA en todos los países donde esta compañía opera.

ADMIRA ha conseguido consolidar un margen bruto (Ebitda) positivo en lo que va de año, a pesar del empeoramiento del entorno del mercado de los medios de comunicación. Al cierre del primer semestre del año, ADMIRA había generado un margen bruto positivo de 69 millones de euros (11.500 millones de pesetas), frente a los casi 10 millones de euros de Ebitda negativo obtenidos entre

6 www.yahoo.es

7 www.yahoo.es 
enero y junio de 2000. Durante el mismo período, los resultados de explotación han pasado de unas pérdidas de 27,8 millones de euros a unos beneficios de explotación de 29,6 millones de euros. El resultado neto de la compañía, sin embargo, sigue estando lastrado por otras partidas como el fuerte endeudamiento o la amortización del fondo de comercio ${ }^{8}$.

«De aquí a finales de año, estos parámetros seguirán presentando una clara evolución alcista, que ratifica que la estrategia de gestión y de posicionamiento de nuestros negocios va por el camino correcto», de acuerdo con lo señalado por los responsables del grupo.

El presidente ejecutivo de ADMIRA, Juan José Nieto, subrayaba durante la presentación del nuevo nombre que estaban entrando en una «nueva era» en la que intentarán una "cohabitación perfecta entre las tres líneas de activos que tiene la empresa: TV y medios en abierto, televisión de pago y contenidos». A pesar de ello, ADMIRA tiene interés en entrar en el negocio de la educación de la mano de Pearson, que es líder mundial en este segmento.

La puesta en marcha de la nueva imagen corporativa del grupo en torno a la marca ADMIRA, se produce tras la aplicación de distintas iniciativas empresariales que han permitido la generación de promociones cruzadas, que benefician a todo el grupo, según los responsables de ADMIRA. «Un ejemplo importante ha sido el acuerdo firmado con Warner para todos nuestros canales de distribución, rompiendo la exclusiva que mantenía con Sogecable» ${ }^{9}$.

Nieto señaló que "ADMIRA ha pasado de ser un conjunto de inversiones en medios y contenidos a una empresa con gestión única, con dos ejes fundamentales de actuación: la comunicación en el mundo en español, y la generación de contenidos a nivel internacional liderada por Endemol ${ }^{10}$.

Según el presidente, Antena 3 sigue siendo una de las mayores fuentes de generación de beneficios para el grupo, pese a que sus resultados para este año se verán afectados por la brusca caída de la publicidad, según reconocen los responsables de ADMIRA. Por su parte, Onda Cero «ha sufrido un profundo cambio de gestión, programación y política de alianzas, que le han permitido obtener un crecimiento espectacular en la audiencia y mejorar sus resultados operativos pese a la crisis del mercado» ${ }^{11}$.

ADMIRA es la sociedad cabecera de la línea de actividad encargada del negocio de contenidos audiovisuales y de medios de comunicación. Agrupa y gestiona las participaciones de TELEFÓNICA, SA en el mercado de servicios audiovisuales europeo e iberoamericano, posicionándose como una de las mayo-

\footnotetext{
8 www.elmundo.es

9 www.elmundo.es

10 www.elmundo.es

11 www.elmundo.es
} 
res compañías en el campo de la producción, tenencia y difusión de contenidos y servicios audiovisuales en el ámbito del mundo de habla hispano-portuguesa.

En el actual entorno de convergencia contenidos/comunicaciones, ADMIRA también se configura como el proveedor de contenidos para el GRUPO TELEFÓNICA, clave para el desarrollo de la estrategia de Internet, telefonía móvil y banda ancha.

Hay que destacar que en el ejercicio 2001, por primera vez en la historia del grupo, el resultado de explotación ha sido positivo, al totalizar 77,1 millones de euros, comparado con los 35,2 millones de euros negativos con que finalizó en el ejercicio anterior. Todo ello a pesar de la coyuntura económica adversa, que tuvo su reflejo en la caída experimentada por el mercado publicitario desde comienzos de ejercicio, y que se vio agravada a partir de los atentados del pasado 11 de septiembre.

\section{DIVISIÓN MEDIÁTICA}

\section{Tv en abierto y radio}

ADMIRA está presente en el área de producción de contenidos a través de las actividades que llevan a cabo Antena 3 Televisión, Vía Digital, Telefé, Canal Azul y Televisoras del Interior. Esta actividad se concreta en la producción de canales temáticos, generación de formatos de programas y contenidos, creación de contenidos interactivos y tenencia y uso de derechos audiovisuales.

La presencia de ADMIRA en esta área de actividad del sector audiovisual se refuerza con su participación en ST-Hilo, dedicada a la producción y transmisión de canales de audio especializados y de música ambiental, y en Lola Films, una de las dos principales productoras cinematográficas españolas.

En el año 2000 también se adquirió una participación del 25\% en la productora española Media Park y del $51 \%$ en la empresa venezolana Rodven, SA entre cuyas actividades destacan un sello discográfico que se explota bajo la marca Líderes y la organización de eventos artísticos. Con estas adquisiciones se ha visto incrementada la capacidad del TELEFÓNICA para la provisión de contenidos a las diferentes «ventanas» de difusión y distribución audiovisual integradas en el Grupo.

\section{- Medios}

En el año 2000 se completaron las adquisiciones pendientes en el sector de la televisión en abierto y radio, con la incorporación de importantes activos en Argentina (Telefé, Radio Continental y aumento de participación en Azul Televisión hasta el 50\% de su capital). En España, esa presencia se concreta en las participaciones accionariales que ADMIRA tiene en Antena 3 Televisión y en Onda Cero Radio.

ADMIRA tiene previsto replicar el exitoso modelo de gestión de Antena 3 en las áreas geográficas en las que comience a estar presente. Este modelo se 
aplica ya con excelentes resultados en los canales de televisión que gestiona en Argentina.

En el año 2000 se completó la compra del 100\% de las acciones representativas de AtCo (Atlántida Comunicaciones) y AC Inversora, sociedades holding que controlan importantes activos del sector de la televisión en abierto en Argentina, entre los que destacan Televisión Federal, SA (Telefé) y Telearte, SA (Canal Azul).

\section{A. Antena 3}

Desde el inicio de la participación de TELEFóniCA en Antena 3 Televisión en julio de 1997, el balance de la gestión ha sido muy positivo. Se ha logrado multiplicar por más de cinco el resultado de explotación de la compañía, pasando de 5.636 millones de pesetas en 1997 a 30.281 en 2000. En 2001, los resultados de Antena 3 se han visto afectados por el deterioro del mercado publicitario en España durante 2001, dentro de una coyuntura económica adversa, agravada a partir de los atentados del 11 de septiembre.

Antena 3 se ha convertido en pocos años en la cadena privada líder en España. La confianza de los espectadores le ha permitido ofrecer a los anunciantes la mejor audiencia desde un punto de vista cualitativo y comercial. Su modelo de programación es el de una cadena dirigida a un público con una clara apuesta por los informativos, el cine y los programas de entretenimientos. Sus profesionales, periodistas y comunicadores, están reconocidos como los más grandes del sector por su rigor y credibilidad.

El equipo directivo apuesta por una innovación constante en la creación de contenidos que entretengan, formen e informen a los espectadores durante 48 minutos por hora. Antena 3 se define como una televisión comercial y familiar, con una programación respetuosa con los valores que comparte la gran mayoría de la sociedad española.

Desde ese punto de partida, su equipo profesional ha creado nuevos caminos, nuevas líneas de negocio que permiten avanzar hacia un ambicioso proyecto multimedia. La cadena ha dado lugar a un completo grupo de comunicación privado de proyección internacional. En ese proceso de expansión, Antena 3 cuenta con el apoyo tecnológico de TELEFÓNICA.

La diversificación en nuevas áreas geográficas y de negocio busca multiplicar e incrementar las fuentes de ingresos y la rentabilidad de la cadena con el fin de consolidar el liderazgo del mercado audiovisual español. Dentro de esta estrategia se ha enmarcado la creación de una Dirección General de Servicios Audiovisuales.

En el ámbito internacional, Antena 3 demuestra su vocación por el mercado de habla hispana. Su Canal Internacional pretende constituir un puente que facilite el conocimiento mutuo entre países y pueblos ligados por una misma lengua. Antena 3 TV tiene también una filial en Perú, Antena 3 TV Perú. 
En marzo de 2002, la Junta General Extraordinaria de Accionistas de ANTENA 3, aprobó la compra de Onda Cero Radio por un importe de 129 millones de euros por los recursos propios. Con esta adquisición, ANTENA 3 recupera el espíritu inicial de la compañía de gestionar conjuntamente negocios de radio y televisión, y se sitúa en la vanguardia de los grupos privados de comunicación que apuestan por liderar el futuro digital del negocio mediático.

Los objetivos que tiene marcados Antena 3 siguen tres líneas principales: consolidación de una posición principal entre las televisiones privadas españolas, reducción de su estructura de costes, política que se complementa con el incremento de los ingresos comerciales y la diversificación en nuevas áreas de actividad: canales temáticos, televisión interactiva y desarrollo de iniciativas comerciales (televenta, licencias y «merchandising», eventos o producción publicitaria). En esta línea, en el año 2000 se avanzó en la diversificación del negocio tradicional con la compra de la importante distribuidora de publicidad para salas de cine, Movierecord.

\section{B. Telefé}

A principios de la década de los 90, la República Argentina inició una profunda transformación en su estructura económica y productiva. Esta iniciativa no tardó en llegar a las comunicaciones, hasta ese momento altamente dependientes del aparato estatal. Así nació Televisión Federal S.A. - Telefe - en 1989, con el propósito de obtener la licencia para la explotación de Canal 11 de televisión abierta en la ciudad de Buenos Aires, objetivo alcanzado cuando el Gobierno licitó esta estación en enero de 1990. El grupo empresario que daba así sus primeros pasos está integrado por una empresa editorial líder en Argentina, Editorial Atlántida, una sociedad conformada por las empresas propietarias de los 10 canales de televisión abierta más importantes del país, Televisoras Provinciales, e inversores institucionales.

A la exitosa operación de Telefe seguiría una continua expansión a nuevos negocios con el acento en la producción y comercialización de contenidos: Radio Continental, con sus frecuencias AM y FM Hit; producción y distribución de señales satelitales a través de facilidades propias de noticias, deportes, entretenimiento y una vasta producción propia de alcance internacional.

Es la principal cadena de televisión argentina que emite en abierto en la Capital Federal y en Gran Buenos Aires. Tiene una audiencia media del 39\% y es la compañía más importantes en la generación de recursos publicitarios en Argentina. En términos de cuota de mercado publicitario, Telefé continúa siendo la cadena líder al alcanzar una cuota del $43 \%$. Sus productos se comercializan en más de 50 países de Latinoamérica, EE.UU, Europa y Asia.

A menos de un año de la privatización, Telefe se convirtió en el líder indiscutido de la audiencia, hecho comprobado por todas las empresas de mediciones de ratings del mercado. Telefe, una estación de televisión abierta cuya señal 
alcanza 8 millones de hogares en Argentina, con facilidades de producción y satelitales propias produce más del $60 \%$ de su programación. Esto se logró con iniciativa, profesionalismo, inversión y tecnología y, muy especialmente, con un sentimiento que está presente en el mismo nombre del canal: fe. Fe en la propia gente, fe en la audiencia y fe en que, juntos, las cosas pueden hacerse mejor.

C. Azul

Telearte, SA, que utiliza el nombre comercial de Azul TV, es el otro activo de televisión argentina que se incorporó a TELEFÓNICA en el año 2000. Es la tercera cadena de televisión en abierto de la República Argentina, con un porcentaje promedio de audiencia del 18,92\% a lo largo del ejercicio 2000. Emite en la Capital Federal y Gran Buenos Aires. Su programación se caracteriza por las comedias, el deporte, los programas de entretenimiento y las noticias.

Canal Azul ha innovado el modelo de televisión argentino al ser pionero en la educación a distancia a través de este medio, difundiendo su programación a las provincias del interior mediante sociedades operativas en Mar del Plata, Resistencia y Paraná (las «Cadenas de Interior»). La participación de ADMIRA en Canal Azul es del 50\%.

\section{E. Onda Cero}

ADMIRA mantiene una importante presencia en el mercado de la radio español y argentino. En España esta presencia se instrumenta a través de las sociedades Uniprex, SA (Onda Cero) y Cadena Voz de Radiodifusión, SA, ambas adquiridas en 1999 y en las que ADMIRA tiene un 100\% de participación. Estas dos sociedades operan en el mercado radiofónico mediante una red de cobertura de cerca de 300 emisoras propias o asociadas que difunden la programación de las cadenas Onda Cero Radio, Europa FM, Onda Melodía, Onda Cero Radio Internacional, Radio Voz y Onda Rambla.

Independientemente de la difícil situación del mercado, es necesario destacar el excelente comportamiento de Onda Cero a lo largo del ejercicio 2001 en términos de audiencia, consolidándose como la segunda opción en el nivel nacional en el mercado radiofónico, con más de 2.771 .000 oyentes, un 18,2\% más que a finales de 2000. A lo largo del ejercicio Onda Cero ha seguido incrementando su red de emisoras gracias a los acuerdos con Radio Blanca y Radio España.

Con la compra de Onda Cero Radio en marzo de 2002 ANTENA 3 recupera el espíritu inicial de la compañía de gestionar conjuntamente negocios de radio y televisión, y se sitúa en la vanguardia de los grupos privados de comunicación que apuestan por liderar el futuro digital del negocio mediático.

\section{F. Radio Continental}

Radio Continental AM 590 y FM Hit 105.5 son las emisoras que hoy en Argentina cuentan con la mayor tecnología. Ambas poseen un sistema interactivo que les permite todo tipo de comunicaciones de ida y vuelta. Alcanzan de forma 
directa un mercado de casi 15.000 .000 personas, ubicándose en el rating entre las tres radios mejor posicionadas del país.

La programación de las dos emisoras se distribuye satelitalmente a las estaciones del interior todos los días, sin interrupciones, a través de la Cadena Continental, integrada en la actualidad por 63 radios. La AM 590 trata todos los temas del momento a través de sus espacios, con «Gente de Radio», los periodistas y conductores más destacados y reconocidos del medio, cumpliendo siempre con la premisa de la radio: entretener e informar, agregándole a través de S.I.C. -Servicio Informativo Continental- información confiable. Los deportes también están presentes con el equipo de periodistas especializados más reconocidos y más premiados de la Argentina. FM Hit, «El poder de la música», se comunica con una nueva generación, poniendo en el aire hoy los temas que otros pondrían mañana. Con programas donde conviven los mejores artistas nacionales e internacionales, los más completos rankings musicales y los programas más exitosos. Este modelo lleva ya más de 4 años de vida, liderando el mercado en los primeros puestos del rating radial.

\section{Tv de pago}

\section{A. Via Digital}

Vía digital, operadora de televisión digital por satélite, comenzó sus emisiones el 15 de septiembre de 1997. Actualmente ofrece más de 70 canales de vídeo, 30 de audio y 16 de radio.

Vía Digital presenta la oferta más variada y competitiva de la televisión digital española, respaldada por una de las tecnologías más vanguardistas del mundo, que se centra en hacer de este nuevo medio un instrumento de comunicación amigable, fácil y accesible. Una opción de ocio en la que el usuario crea, para él y para su familia, una televisión a su medida.

Vía Digital es una oferta multitemática, ya que los canales que forman nuestra parrilla abarcan gran variedad de géneros y la mejor selección de ocio y servicios. Canales temáticos de cine, deportes, música, infantiles y juveniles, informativos, de documentales, de cocina, de belleza y moda, y un largo etcétera, concebidos especialmente para la audiencia española, garantizan que cada miembro de la familia encuentre en Vía Digital sus programas favoritos a un precio muy competitivo. Esta oferta se compone de contenidos especialmente seleccionados o creados para el telespectador español: el mejor y más reciente cine español e internacional, además de aquellos eventos con mayor demanda entre los telespectadores, como la Champions League, el Mundial de fútbol del 2002, la liga española y la Copa del Rey, la Copa de la UEFA, el torneo de tenis de Wimbledon, el circuito de golf US PGA, las mejores ferias taurinas, los más interesantes combates de boxeo, el preestreno en exclusiva de las series para televisión más esperadas, las óperas y conciertos del Liceu de Barcelona y un amplio abanico de 
canales especializados en el mundo de la mujer, la caza y la pesca, la compraventa, los temas económicos, financieros y culturales, los más modernos dibujos animados y programas infantiles, los informativos más completos y los documentales más emocionantes.

TELEFÓNICA inició la comercialización de su oferta y emisión de televisión digital vía satélite en septiembre de 1997, a través de la sociedad DTS Distribuidora de Televisión Digital, SA, que comercializa servicios de televisión de pago bajo la marca Vía Digital. Desde el comienzo de su actividad, mantiene una línea de crecimiento en el número de abonados. Actualmente distribuye 65 canales de televisión, 30 de audio y servicios interactivos y, a finales de diciembre de 2000, contaba con 633.000 abonados.

En junio de 1999, TELEFÓNICA y Sogecable suscribieron un acuerdo sobre la explotación de los derechos televisivos y audiovisuales de los partidos de fútbol del Campeonato Nacional de Liga y de la Copa de SM el Rey hasta la temporada 2008/2009. Este acuerdo también incluye la explotación de los derechos de los partidos de la Champions League de las temporadas 2000/2003. En el año 2000 la programación de Vía Digital se reforzó de forma significativa añadiendo a estos derechos audiovisuales deportivos el Mundial de Fútbol de 2002 y los derechos de la competición europea de baloncesto para la televisión de pago.

Por otro lado, la adquisición de los derechos de emisión de películas de las grandes compañías norteamericanas y de las productoras españolas permite a Vía Digital contar con una cartelera cinematográfica muy atractiva para el cliente, en la que figuran los títulos más premiados en los grandes festivales de cine. Durante el año 2000, Vía Digital también incluyó en su programación servicios interactivos para gestiones bancarias, compra de entradas, información de bolsa, meteorológica y publicidad interactiva.

Como sistema de satélites, Vía Digital opera con Hispasat, que ofrece la mejor cobertura para España, incluyendo las Islas Canarias. Esto permite garantizar una recepción óptima aun con antenas de muy pequeña dimensión.

\section{B. ASA}

ADMIRA dirige su línea de actividad de provisión de sistemas y servicios audiovisuales a través de la sociedad ADMIRA Servicios Audiovisuales (ASA), en la que participa como accionista único, y mediante su participación en la compañía Hispasat $(22,74 \%)$, empresa gestora del sistema de comunicaciones por satélite del mismo nombre.

ASA concentra su actividad en tres áreas de negocio: servicios audiovisuales (plataformas técnicas de televisión digital, redes de contribución y distribución, televisión de negocios...), sistemas audiovisuales (diseño, ingeniería, integración y puesta en operación de telepuertos, plataformas técnicas, unidades móviles...) y servicios de producción. La compañía, que ha iniciado un proceso de 
expansión dirigido a los mercados de Perú, Argentina y Brasil como cabecera de su futuro despliegue en toda Latinoamérica, está preparada para prestar servicios de difusión de la televisión digital terrenal.

\section{Hispasat}

Los grandes operadores de telecomunicaciones españoles e internacionales como TELEFÓNICA, British Telecom, France Telecom, entre otros, utilizan los satélites Hispasat para ofrecer a sus clientes servicios de comunicaciones por satélite tales como: distribución de las cadenas españolas de televisión, distribución de las señales de las grandes cadenas españolas de radio, contribución de TV desde Europa y América, difusión de datos, implantación de redes empresariales, VSAT, redes de teleimpresión de periódicos y redes de control medioambiental.

Hispasat lidera el programa europeo Digisat, en el desarrollo de la Interactividad por Satélite asociada a la TV Digital. Hispasat colabora, asimismo, en otros programas europeos ACTS como Talismán, Cinenet, DigismaTV, etc. El nuevo marco liberalizador de las comunicaciones por satélite está propiciando el desarrollo de innovadores servicios como la TV Digital; lo que ha suscitado una fuerte demanda de capacidad espacial.

En diciembre del 1996 la sociedad Hispasat entraba en beneficios y a lo largo del 97 ha llegado a la plena ocupación de sus dos satélites. Al final de la vida útil de los dos primeros satélites del sistema Hispasat se habrán conseguido unos ingresos totales de 130.000 millones de pesetas y un Cash Flow de 84.000 millones de pesetas. Un dato a destacar es el del Cash Flow generado por el sistema Hispasat que ha sido positivo desde la entrada en explotación de los dos satélites. Estas cifras muestran claramente la solidez económica del sistema Hispasat que le permitirán afrontar su consolidación definitiva con la puesta en órbita del tercer satélite y de las futuras unidades de vuelo de la segunda generación del sistema Hispasat, que le permitirán hacer frente a las nuevas demandas de los operadores, tanto en Europa como en América.

\section{Contenidos}

- Música

\section{A. Szena}

Es una compañía que se dedica a la gestión del talento, la contratación artística, los eventos y la música. Sus diferentes áreas permiten ofrecer una solución integral «llave en mano» dentro del mundo del espectáculo, la música y el ocio en general. ADMIRA tienen el 100\% de las participaciones de la empresa.

Szena tiene su sede central en Madrid y está en plena expansión hacia los mercados Latinoamericanos. Sus últimos éxitos han sido la gira de Julio Iglesias en España y el «Premio Ondas» conseguido por Carlos Bautes. 


\section{B. Rodven}

Rodven tiene por objetivo generar proyectos musicales de éxito en el mercado de habla hispana y Brasil, así como el descubrimiento y desarrollo de nuevos artistas. Esta empresa, de la que ADMIRA posee el $51 \%$ de las participaciones, tiene sedes en Colombia, Venezuela, EEUU, Brasil y España.

\section{- Productoras tv}

\section{A. Endemol}

La unidad de negocio de los contenidos, el principal activo de las empresas del sector audiovisual, centra su actividad en torno a la compañía Endemol, con el objetivo de convertirse en el centro neurálgico de los contenidos de ADMIRA.

Endemol, adquirida por TELEFÓNICA en julio de 2000, es una empresa que opera en el ámbito del desarrollo y producción de contenidos para televisión en abierto, televisión de pago e Internet.

En el área de negocio de televisión en abierto la sociedad ofrece una amplia oferta de contenidos, con una destacada orientación comercial. En la línea de negocio de televisión de pago centra su actividad en el empaquetado de canales temáticos y «premium», con la finalidad de ofrecer a los clientes soluciones imaginativas para sus necesidades de ocio y entretenimiento.

En el área de Internet, Endemol diseña contenidos específicos con soluciones interactivas, "reality shows» de 24 horas, etc., tratando de conseguir otros ingresos complementarios de la actividad comercial generada por los programas.

Endemol se encarga de la producción de programas y formatos televisivos con especial presencia en Holanda, España, Italia, Portugal y Escandinavia, y está dentro de las tres primeras empresas en todos los países donde opera.

Aunque Endemol siempre ha considerado Europa como su mercado natural, controlando las empresas productoras locales con más presencia y cuota de mercado en cada país, durante el ejercicio 2001 ha continuado su expansión internacional con la finalidad de convertirse en líder en aquellos países que constituyen el mercado natural del Grupo ADMIRA en los que todavía no estaba presente. En ese sentido, son destacables los acuerdos a los que se llegó con dos de los grupos mediáticos más importantes de Latinoamérica: TV Globo en Brasil y Grupo Televisa en México. Con estos acuerdos la presencia de Endemol en Latinoamérica aumenta de forma sustancial.

\section{B. Media Park}

Es un centro proveedor de contenidos audiovisuales y multimedia para los New Media. Entre los servicios que ofrece se encuentran la producción, gestión y comercialización de contenidos para todos los medios de distribución (TV digital e intenet). ADMIRA posee una participación del $25 \%$. 


\section{- Cine}

\section{A. Lolafilms}

Fundada en 1981, Lolafilms se ha convertido en poco tiempo en la productora independiente más destacada de España. Dirigida por Andrés Vicente Gómez, Lolafilms ha producido películas de los directores españoles más importantes.

Con socios de la talla de TELEFÓNICA, el gigante de las telecomunicaciones, el Grupo Editorial Planeta y Gescapital, una prestigiosa gestora de patrimonios, la productora se encuentra en este momento en plena expansión de sus actividades en el campo audiovisual, iniciada por la fundación de Lolafilms Distribución, responsable de la llegada a las salas tanto de sus propias producciones como de sus adquisiciones internacionales. Siguiendo con sus planes de expansión, Lolafilms ha abierto oficinas en Londres con el nombre de Lolafilms UK Limited. Desde allí se centralizarán todas sus actividades internacionales y se llevará el desarrollo de los proyectos en lengua inglesa.

Lolafilms UK Limited se hará cargo también de las ventas internacionales, de las adquisiciones para España y de los mercados internacionales. El primero de esos proyectos en lengua inglesa es «Esa Chica de Río.

Lolafilms ha comenzado también su andadura como productora de televisión con la serie policial «Petra Delicado», que está coproducida con la cadena nacional Tele 5, en la que se emite. También en coproducción con Tele 5, Lolafilms produce «La Gran Ilusión», un programa dedicado al cine que ha comenzado su andadura en el 2001. Lolafilms está formada por un equipo de profesionales con muchos años de dedicación a la industria del cine, y liderada por Andrés Vicente Gómez.

\section{B. Patagonik}

La actividad principal de Patagonik es la promoción y producción de películas. Patagonik produce actualmente el $10 \%$ de las películas argentinas y prevé aumentar su participación de mercado pasando del 33\% de los espectadores de cine argentino conseguido en 1998 al 47\% en el año 2000.

En 1998, Patagonik contó con 1.280.000 espectadores en las salas de cine para un total de 3 películas («Sus ojos se cerraron», «Cohen vs. Rosi» $\mathbf{y}$ «Dibu II»). Patagonik tuvo en 1998 una cuota de mercado por ingresos en taquilla del $29 \%$ sobre la recaudación total del cine argentino, que en 1998 ascendió a 18.645 millones de dólares.

Si bien en el año 1999 Patagonik no produjo ninguna película ante la incertidumbre originada en relación con los créditos industriales concedidos por el Instituto Nacional de Cine y Artes Audiovisuales («INCAA»), en el año 2000 Patagonik ha estrenado la película de animación «Condor Crux» y tiene prevista la producción de otros tres proyectos, uno más de animación: (Pintín) y tres películas con actores de prestigio internacional argentinos y extranjeros. En la 
producción cinematográfica hay que considerar dos conceptos básicos: la financiación del proyecto y la recuperación de la inversión. Para el estadio de producción se busca básicamente la financiación que, a través de créditos industriales «blandos», concede el INCAA. El subsidio tiene como límite el 100\% de los costos de producción documentados de la película considerada. En cuanto al ciclo de explotación de películas de cine, las fases que se distinguían para Lolafilms en la sección son aplicables igualmente para el negocio de Patagonik.

Asimismo, Patagonik se comprometió mediante carta de 10 de octubre de 1997 a no coproducir películas con otra entidad americana distinta de Buena Vista Film Production (Latin America), S.A. no imponiéndose restricciones para realizar coproducciones con compañías europeas. Por otra parte, Patagonik tiene un contrato de licencia en exclusiva con Artear, para la distribución de las películas a través de televisión (a excepción de las ventanas "pay per view», «premium» $y$ «network») en América Latina e Islas del Caribe. Asimismo, el acuerdo de accionistas de Patagonik prevé la firma de acuerdos de distribución con Antena 3 y Vía Digital para el mercado español de televisión abierta y de pago (incluyendo premium y pay per view).

\section{- Interactivos}

\section{A. ST-Hilo}

Llevan más de 30 años ocupándose del cable, desde 1970 al 2002. Por eso, dicen que: «Tenemos el Hilo más largo, más musical, con más experiencia y que más se oye».

ST\&HILO es una empresa del GRUPO TELEFÓNICA, adscrita a TELEFÓNICA MEDIA, dedicada a comercializar el servicio Hilo Musical, que transmite, vía cable telefónico, seis canales musicales orientados a la ambientación sonora de locales públicos, de trabajo y domicilios particulares mediante la emisión de contenidos eminentemente musicales durante 24 horas al día, todos los días del año y sin ningún tipo de interrupción publicitaria.

ST\&HILO dispone de una Red Comercial propia, especializada, repartida en treinta y seis provincias del territorio nacional organizadas en seis Con esta estructura y con 600.000 oyentes, Hilo Musical se sitúa como líder indiscutible en el mercado de la música: somos la Música y llevamos la Música. Su evolución y esfuerzo para mantenerse como líder le lleva a la Red con un doble objetivo: dar un mayor servicio a nuestros abonados y ofrecer a nuestros amigos un entorno musical, creando un servicio de información musical especialmente diseñado para Internet e Infovía, que ponga a disposición de todos nuestra experiencia y conocimientos adquiridos a lo largo de todos estos años de trabajo.

\section{B. Art Media Company}

Con el lema «Convertimos lo lejano en inminente», Art Media es una 
empresa dedicada a ofrecer una amplia gama de servicios y soluciones integrales de comunicación multimedia basados en las más avanzadas tecnologías. Con ello da respuesta a sus necesidades más precisas, a la vez que se anticipa a sus demandas futuras.

Dedica su esfuerzo diario a cumplir sus compromisos con la máxima calidad, tanto en prestaciones como en fecha, y con un coste competitivo.

Art Media ofrece: producción Multimedia on line, producción Multimedia off line, producción audiovisual y televisión interactiva.

\section{- Deportes}

\section{Derechos de explotaciones deportivas}

Reúne y gestiona los derechos de las explotaciones deportivas de todo el GRUPO ADMIRA. Es propietaria del $40 \%$ de Audiovisual Sport, entidad que posee los derechos para la explotación de competiciones futbolísticas, entre las que cabe destacar la liga española de fútbol. Dentro de la explotación de derechos de televisión de fútbol hay que anotar también los activos que ostenta ADMIRA en Argentina a través de la empresa Torneos y Competencias (20\%), propietaria de los derechos de televisión de la liga argentina de fútbol.

\section{A. Admira Sport}

\section{- Euroligue de Baloncesto}

El producto estrella de Admira Sport es la Euroliga de Baloncesto. Se trata de una experiencia líder en el ámbito europeo de creación de una estructura profesional para poner en práctica una competición que desarrolla el deporte profesional en el continente europeo. Supone una integración en la producción de contenidos de calidad controlando la competición y sus derechos con una difusión multimedia. Ésta cuenta con los mejores equipos europeos y Admira Sport gestiona la totalidad de los derechos audiovisuales, Internet, publicidad, patrocinio, «merchandising», etc. Para ello ha constituido una sociedad, Euroleague Marketing, junto a la Unión de Ligas Europeas de Baloncesto, que congrega a los clubes, y Mediapro. La participación de ADMIRA en esta sociedad es del $70 \%$.

\section{B. Audiovisual Sport}

Audiovisual Sport, s.l. (AVS) se constituyó el 21 de enero de 1997 y es la sociedad propietaria de los derechos de emisión del fútbol de Primera División y Segunda A, tanto en los partidos del campeonato español de Liga como de la Copa del Rey, excepto la final. Estos derechos expiran al final de la temporada 2002/2003. Audiovisual Sport emite ocho partidos de cada jornada de Liga en la modalidad de pagar para ver (PPV).

Las Televisiones Autonómicas y Canal+ retransmiten los otros dos partidos, uno cada uno, después de haber firmado sendos contratos con Audiovisual Sport. TELEFÓNICA MEDIA posee un $40 \%$ del capital. 


\section{C. $\mathbf{T y C}$}

Torneos y Competencias S.A. es una empresa dedicada a la difusión y el crecimiento del deporte a través de la producción y emisión de programas de radio y televisión, de la adquisición y comercialización de derechos de transmisión, de la organización de eventos y espectáculos deportivos, y de la oferta de productos relacionados con estas actividades.

La empresa se encuentra abocada a la planificación de proyectos que faciliten la práctica de deportes a toda la comunidad, como también a la búsqueda de jóvenes con valores deportivos potenciales a los que Torneos y Competencias pueda apoyar para el desarrollo de su carrera, en pos del ambicioso objetivo de sentar las bases para una nueva generación de argentinos amantes de las actividades deportivas y capacitados para competir a nivel internacional.

Torneos y Competencias es la empresa vinculada al deporte más importante de Argentina. Es reconocida por su trayectoria, por su capacidad técnica y comercial, por su respaldo económico-financiero y por su creatividad y eficiencia en la producción de contenidos radiales y televisivos, en la organización de espectáculos y eventos y en el desarrollo de negocios vinculados al deporte. Y es, sin duda, la empresa más indicada para difundir y promoverlas.

\section{- Educación}

\section{A. Educamedia}

ADMIRA ha asumido voluntariamente un fuerte compromiso social en todos los territorios en los que opera. En la sociedad actual el acceso a las tecnologías, y muy especialmente a las telecomunicaciones, es imprescindible para el desenvolvimiento normal de las sociedades y de los individuos. La carencia de estos servicios es sinónimo de atraso social y personal y, por ello, las telecomunicaciones se han convertido en el índice más fiable para juzgar el desarrollo de una comunidad.

Con esta percepción clara, TELEFÓNICA se ha marcado objetivos para desarrollar al máximo las aplicaciones sociales de la tecnología con el fin de fomentar la igualdad de oportunidades y contribuir a mejorar la vida de personas y colectivos sociales, con especial atención a los grupos más desprotegidos y necesitados.

Esta tarea social y cultural está encomendada a la Fundación Telefónica, con proyección en España, Argentina, Brasil, Chile, Perú y Marruecos. En todos estos países ofrece y desarrolla proyectos y actividades en consonancia con las respectivas realidades nacionales a través de entidades fundacionales autónomas, pero vinculadas por una misma filosofía, unos objetivos comunes y una metodología de trabajo similar.

Creada en 1988, la Fundación Telefónica promueve actividades en los terrenos de la educación, las aplicaciones sociales de las telecomunicaciones, 
inserción social, desarrollo comunitario, promoción del voluntariado y otros. Además, se caracteriza por su cooperación con las organizaciones de reconocido prestigio en cada uno de los países, en los que desarrolla y ejecuta los proyectos.

La promoción y el acceso a la educación y la cultura es una de las líneas principales de la Fundación. En este ámbito se inscriben las colaboraciones con el Instituto Cervantes y la Real Academia Española, la Biblioteca Nacional, la Biblioteca de Cataluña, la Abadía de Monserrat o el Palau de la Música entre otras instituciones, así como sus múltiples exposiciones y actividades de producción y difusión del arte.

Dentro del ámbito educativo cabe destacar el proyecto EducaRed, que se propone fomentar el uso educativo de Internet facilitando la conexión a la red e infinidad de servicios educativos para alumnos, padres y profesores de centros públicos, privados y concertados de toda España. EducaRed aglutina la totalidad de integrantes de la comunidad educativa del Estado en España y es el portal educativo en Internet con mayor implantación en lengua española. Actualmente el programa está en fase de adaptación en Argentina, Brasil, Chile y Perú (Eduvía, Educarede, Internet Educativa y Edured, respectivamente).

Educavía es la empresa del Grupo en el ámbito de la educación. Dentro del área de contenidos, su actividad se centra en la creación de cursos de formación individualizada dedicados a los ámbitos universitario y empresarial. Estos contenidos pueden generarse, también, mediante acuerdos con universidades u otros proveedores.

La difusión de los contenidos educativos se hará «On line»a través de los medios de comunicación del grupo, incluidos los portales de la red. El ámbito de actuación de Educavía son los mercados hispanoamericanos, de habla española y portuguesa. ADMIRA posee una participación del 100\% de Educavía.

En este mismo contexto, la Fundación TELEFÓNICA ha contribuido también a la creación del portal universitario CampusRed, cuyo fin principal es servir de plataforma de colaboración entre los profesores y alumnos de las universidades del ámbito latinoamericano.

Entre las acciones humanitarias de la Fundación TELEFÓNICA, cabe mencionar el apoyo a los servicios telefónicos de asistencia social, así como el desarrollo de la Red Internacional de Solidaridad y de proyectos favorecedores de la integración laboral, como Merc@dis, en el que se ofrece una bolsa de empleo para personas con discapacidad. Asimismo, la Fundación TELEFÓNICA invierte en programas de inserción social a través del trabajo y de apoyo a las personas «sin techo». En el año 2000, además, ha provisto de teléfonos y unidades de emergencia para paliar catástrofes como las inundaciones de Venezuela, Mozambique y la India, así como el hambre de Etiopía y el terremoto de El Salvador. 


\section{- Infantil}

\section{A. Megatrix}

Es la filial al 100\% de Antena3 que agrupa contenidos y negocios de carácter infantil. Emite diariamente un programa de dos horas y los fines de semana, de diez. En Vía Digital posee un canal temático que emite cinco horas diarias. Edita una revista con línea editorial propia y organiza eventos deportivos infantiles, tales como el Torneo de Tenis Megatrix. Actualmente está en fase de expansión en Iberoamérica. Las primeras emisiones para este mercado las realiza en Telefé, cadena de televisión líder en Argentina.

\section{- Otros}

\section{A. Pearson}

Pearson plc es una compañía internacional de medios de comunicación, líderes de mercado en educación, información mercantil estratégica, producción internacional de televisión y publicaciones de consumo.

Las operaciones mundiales de Pearson son: Pearson Education, Penguin Group, FT Group, Pearson Television.

Pearson Televisión es el principal productor internacional de televisión del mundo. Posee la mayor selección mundial de formatos de concursos, es el más importante productor de series dramáticas y realiza una amplia variedad de programas de entretenimiento que incluyen aventuras, acción y comedias de situación. La mayor parte de estos programas son realizados a nivel local, empleando personal de producción de cada país, y adaptando su formato a los respectivos idiomas y culturas.

Con más de 150 programas producidos en más de 30 países de todo el mundo, dicha producción televisiva genera más del $70 \%$ de los beneficios anuales de Pearson Televisión, que ha crecido rápidamente durante los últimos cuatro años gracias a diversas adquisiciones y, aunque sus operaciones de producción son completamente internas, sus programas son producidos por varias empresas subsidiarias que incluyen a Thames TV, Grundy y Fremantle.

\section{B. Movierecord}

Movierecord comenzó en el mercado publicitario español en 1952, siendo la primera empresa que normalizó y garantizó la posibilidad de hacer campañas de publicidad en cines en toda España. Desde entonces hasta nuestros días Movierecord se ha mantenido como líder en el mercado de las exclusivas publicitarias on line. Actualmente tiene una cuota de mercado superior al $50 \%$ con más de 1.600 pantallas en toda España.

El 27 de Septiembre de 1999 Movierecord pasó a formar parte del Grupo Antena 3 y, por tanto, de ADMIRA. La pertenencia al mayor grupo de comunicación del país les aporta todo su conocimiento, experiencia, recursos, fuentes de información, servicios de marketing... 


\section{Servicios Audiovisuales (TESA)}

Telefónica Servicios Audiovisuales es la empresa el GRUPO TELEFÓNICA proveedora de servicios y sistemas de comunicación audiovisual.

Creada para satisfacer las exigencias del mercado audiovisual, posee la capacidad propia, la experiencia y el conocimiento técnico necesario para formular sus ofertas de productos y servicios en cualquier lugar del mundo.

Gracias a la constante aplicación de la calidad en sus procesos, a la utilización permanente de las tecnologías existentes, así como a la disponibilidad y al espíritu innovador de su equipo humano, ofrece respuestas flexibles que, bajo la filosofía «llave en mano», se adaptan perfectamente a las necesidades de cada cliente.

Telefónica Servicios Audiovisuales realiza la producción y transmisión de la señal audiovisual ofreciendo siempre el servicio más completo, gracias a su experiencia, capacidad y especialización. La oferta incluye todos los procesos necesarios para satisfacer las demandas más complejas, incorporando a los proyectos audiovisuales los últimos avances.

\section{PERSPECTIVAS}

La celeridad con la que TELEFÓNICA creó, mediante sucesivas compras, su grupo de medios difícilmente podría dar resultados inmediatos. La estrategia, basada también en una apuesta política, contemplaba un amplio margen de resistencia, propio de la fortaleza de la compañía de telecomunicaciones. Consecuencia de esa etapa de adquisiciones compulsivas fue la rápida envergadura que adquirió TELEFÓNICA en el ámbito de los medios, pero también unos precios de compra extremadamente elevados por empresas que, en el caso de ser rentables, quedarían lastradas por esa circunstancia de partida.

Las pérdidas de la compañía en el sector de los medios podrían llevar, según continuados rumores, a la venta de gran parte de sus activos, con la consiguiente renuncia a los objetivos que, en un sentido amplio, definen la economía de gama de las corporaciones globales. En su informe a la Comisión Nacional del Mercado de Valores TELEFÓNICA señala que perdió en 2000 más de 104 mil millones de pesetas en su división mediática. En el panorama nacional, el déficit más elevado lo ha vuelto a registrar Vía Digital (42.222 millones de pesetas), que opera sobre la estructura delicada y frágil de la nueva televisión nacida de un sistema regulatorio que parecía favorecer los intereses emergentes de la compañía de telecomunicaciones. TELEFÓNICA, por el contrario, ganó más de 20.000 millones en su televisión convencional, Antena 3-. Las mayores pérdidas en 2000 se registraron en Argentina, donde el conjunto de las actividades audiovisuales arrojaron un saldo negativo de 86.000 millones de pesetas. Además de Antena 3, arrojaron beneficios la productora holandesa Endemol (10.762 millones), adquirida por cerca de un billón de pesetas, valor que no se sostiene en el mercado, y 
23.201 millones procedentes de su 5 por ciento en Pearson, propietario de Recoletos.

\section{Acuerdo con Sogecable}

En mayo de 2002, Sogecable y TELEFÓNICA llegaron a un acuerdo para la integración de sus plataformas digitales. Esta integración se inscribe en el marco del proceso de racionalización de la televisión de pago y de la industria de contenidos, en curso tanto en España como en los mercados de su entorno. La unión de ambas compañías dará lugar al operador líder en España de la televisión de pago, con más de 2,5 millones de hogares-clientes e ingresos agregados del año 2001 de más de 1.300 millones de euros. El acuerdo constituye un paso muy significativo en el desarrollo del mercado audiovisual español y favorecerá la implantación más acelerada de los sistemas digitales en los hogares, para beneficio tanto de los usuarios como de la industria. Aun así, hasta el otoño de 2002 no se podrá llegar a fijar del todo la fusión de ambas plataformas digitales ya que hace falta el visto bueno del Gobierno Central y del Parlamento, según señaló Flor Puente, Jefe de Comunicación y RR.II. del Grupo ADMIRA.

Por otra parte, el grupo de comunicación pretende seguir manteniéndose como líder en el sector de los contenidos en los mercados de habla hispana y lusa.

\section{CONCLUSIONES}

Partiendo de lo expuesto anteriormente, hemos de estacar diversas cosas:

El grupo ADMIRA MEDIA es el elemento idóneo para hacer frente al gigante por excelencia del mercado comunicacional español durante más de 25 años, PRISA. Así, desde su creación, allá por mediados de los años noventa, la hace poco bautizada con el nombre de ADMIRA MEDIA se ha convertido en uno de los tres grandes grupos mediáticos españoles junto con PRISA y el grupo Correo-Prensa Española. Aunque se encuentra alejado de los negocios de comunicación escrita, en lo que se refiere al sector audiovisual, ADMIRA MEDIA posee dos ases en su manga para competir con el grupo de Jesús de Polanco, Onda Cero contra la SER y Antena 3 TV ante Canal +.

Es significativo que la expansión de este grupo de comunicación en el mercado nacional e internacional coincide con el cambio de gobierno en España y la llegada al poder de un partido político afín a las ideas de la Compañía.

ADMIRA MEDIA ha seguido durante estos años dos tipos de estrategias. Así, sin abandonar las estrategias de crecimiento externo de tipo relacionales (alianzas) y de apropiación (fusiones, absorciones y toma de participaciones), que se pueden ver claramente en las diferentes empresas en las que participa el grupo que en los apartados anteriores se nombran, el grupo ha aplicado la estrategia de internalización, sobre todo en lo que al mercado de habla hispana 
y portuguesa se refiere ${ }^{12}$. Así, ADMIRA MEDIA es en la actualidad el líder de este sector en el nivel mundial, como señalaban desde el gabinete de comunicación de la empresa, objetivo que ya el ex presidente de la Compañía, César Alierta, resaltaba en su discurso ante la Junta General de Accionistas de TELEFÓNICA, S.A. el 15 de junio de 2001 cuando tomaba las riendas de la empresa al decir que era su "responsabilidad y reto crear hábitos de consumo a través de contenidos multiplataforma y marcas líderes en el mundo de habla hispana ${ }^{13}$ ”.

De la misma forma, Alierta señalaba también que "el conjunto de compañias productoras de contenidos de TELEFÓNICA MEDIA- entre las que se encuentra Endemol- junto con Terra Lycos, jugarán un papel central en la estrategia de convergencia de TELEFÓNICA hacia lo que se ha definido como "nueva media ${ }^{14}$ '”. Esto viene a resaltar el enorme interés que la Compañía tiene en los negocios de generación de contenidos, hecho que confirman las participaciones que el grupo posee en empresas de este tipo, entre las que se encuentran las corporaciones que generan contenidos musicales, cinematográficos y deportivos entre otros, en todo el mundo, no sólo en España. A la producción de contenidos hay que unirle también la difusión de los mismos. Sin embargo, ADMIRA, aunque con una excelente presencia internacional, es aún un pequeño "conglomerado" en comparación con otros como Vivendi Universal o Time Warner.

Todo parece indicar que el grupo ADMIRA MEDIA es uno de los grandes grupos de comunicación de España con relaciones internas y externas con otras empresas nacionales e internacionales. Así, las adquisiciones y fusiones realizadas por la empresa en estos últimos años muestran una clara supremacía sobre inversiones creadoras de nuevas capacidades, siendo ésta, como señala Delgado, la forma de reestructuración más importante con la que el capital hace frente a las crisis que la empresa ha vivido, sobre todo tras el último escándalo surgido en el seno de la presidencia de la Compañía por la compra de unas acciones por parte de un familiar del ex presidente de ADMIRA.

Pero como viene ocurriendo desde hace unos 20 años, como señala Delgado Cabeza Manuel, el Catedrático de Economía Aplicada de la Universidad de Sevilla, en el cuaderno de economía y sociedad "Desde el Sur" que editan la Universidad Hispalense y su homóloga de Málaga, los mercados son muy competitivos y cambiantes, con una demanda que se ha vuelto inestable, a veces volátil

12 CARO GÓNZALEZ, Francisco Javier y OVIEDO GARCÍA, Ma Ángeles: La industria de la Comunicación. Sus estrategias de crecimiento en una economía globalizada. Universidad de Sevilla, Sevilla, 1999, pp. 83-95.

13 Discurso Presidencial ante la Junta General de Accionistas de telefónica, S.A. de César Alierta: 15 de junio de 2001.

14 Discurso Presidencial ante la Junta General de Accionistas de telefónica, S.A. de César Alierta: 15 de junio de 2001. 
y / o próxima a la saturación, alcanzar o mantener cuotas importantes, y hacer posible la necesaria expansión se convierten en una función clave. Debido a esto, las grandes empresas, entre las que se encuentra ADMIRA MEDIA, coinciden en expandirse mundialmente, mediante lo cual, las grandes corporaciones se han convertido en los "directores de orquesta" en la red de transacciones internas y externas a la misma, pero cuyo interés es promover sus intereses globales ${ }^{15}$. En el caso de ADMIRA, su objetivo es ser líder en el mundo de los contenidos de habla hispana y lusa.

ADMIRA no es ya una empresa nacional, poco a poco y mediante largos procesos de concentración y centralización del capital ha pasado a ser el protagonista, el principal soporte organizacional de la misma y el artífice principal de los cambios que la estructura económica española y mundial está experimentando. Así, ADMIRA, como los grandes grupos de comunicación, no deja de crecer en la economía mundial, debido sobre todo al impulso dado por las nuevas tecnologías aparecidas en los últimos años, creando así una "empresa sin fronteras" en un "mundo sin fronteras", el mundo de la Globalización. Este término apareció en los años 80 en las grandes escuelas americanas de gestión de empresas, -Columbia, Harvard, Stanford- y se ha extendido desde entonces para hacer referencia a los procesos en los que el sistema económico se encuentra inmerso, cuyas connotaciones e interrelaciones con otros ámbitos -lo social, lo político, lo cultural - generan una dinámica que condiciona y modula cada vez en mayor medida la vida de los pueblos ${ }^{16}$.

Según Manuel Delgado los grandes grupos multimedia son los nuevos amos del mundo y destaca que éstos habían entrado en una dinámica de alianzas, fusiones, absorciones y concentraciones, tratando de tomar posiciones en el dominio de una infraestructura de la información global. La estrategia de estos grandes grupos de comunicación trata de dominar toda la cadena del proceso hasta llegar a la difusión y relación con los usuarios de la comunicación, ahora mercancía generada a gran escala por medios cada vez más condicionados en la calidad de sus productos y en su independencia, como consecuencia de su imbricación en grandes entramados empresariales y de su sujeción a las leyes del mercado." ${ }^{17}$

En definitiva, ADMIRA MEDIA es un grupo de comunicación español con clara y fuerte presencia tanto en los mercados mundiales como internacionales, sobre todo en los de habla hispana y lusa, donde es líder. Un liderazgo que emana de las excelentes estrategias trazadas para alcanzar dicho lugar en los mercados

15 DELGADO CABEZA, Manuel: La Globalización, ¿nuevo orden o crisis del viejo?, Desde el Sur, cuadernos de economía y sociedad, Málaga, Mayo 1998.

16 Ibídem.

17 Ibídem. 
mediáticos mundiales y cuya principal baza se encuentra en la producción de contenidos y la aplicación a estos de la última tecnología aparecida en el mercado.

\section{Bibliografía:}

- AUSBANC: «Los nueve gigantes de la comunicación» Madrid, $\mathrm{n}^{\circ}$ 1, Marzo, 2002.

- DELGADO CABEZA, Manuel: La Globalización, ¿nuevo orden o crisis del viejo? Desde el Sur, cuadernos de economía y sociedad, Málaga, Mayo, 1998.

- Grupo Zeta: Informe anual de la Comunicación (2000-2001),; Grupo Zeta, Madrid, 2001.

- Inter Medios Monográficos: Vensolce, Madrid, nº 1, Enero, 2002.

- REIG, Ramón: Medios de comunicación y poder en España: prensa, radio, televisión y mundo editorial. Paidós PC, Barcelona, 1998, pp. 75-96.

- CARO GONZÁLEZ, Francisco Javier y OVIEDO GARCÍA, Ma Angeles: La industria de la Comunicación. Sus estrategias de crecimiento en una economía globalizada, Universidad de Sevilla, Sevilla, 1999.

- Discurso Presidencial ante la Junta General de Accionistas de Telefónica, S.A. de César Alierta: 15 de junio de 2001.

- www.admira.com

- www.elmundo.es

- wWw.estrelladigital.com

- www.reuters.com

- www.telefonica.es 